\title{
Effects of jianwei qiweibaizhusan on the intestinal microorganisms and enzyme activities
}

\author{
GuangXian Cai', Ao Zeng ${ }^{1}$, NenQun Xiao', SaiNan Zhou' ${ }^{1}$ KangXiao Guo' and ZhouJin Tan ${ }^{\text {* }}$ \\ ${ }^{*}$ Correspondence: tanzhjin@sohu.com \\ ${ }^{1}$ Hunan University of Traditional Chinese Medicine, Changsha, Hunan province, 410208, PRC.
}

\begin{abstract}
Chinese medicine prescriptions are composed of a variety of Chinese herbal medicine in a compatible format. Because of the complexity of Chinese medicine prescription, we could study it more precisely by minus one herbal medicine of the prescriptions. To study the effects of Jianwei Qiweibaizhusan, Sijunzitang and Qiweibaizhusan on intestinal microorganisms and enzyme activities, and to confirm the scientific property of prescription compatibility on Qiweibaizhusan, microbial culturing methods and enzymological methods were used to determine the number of microbes and enzyme activities in gastrointestinal tract. 70 Kuming mice were randomly divided into 7 groups: the control group, the antibiotics treated group, the minus agastache group, the minus costustoot group, the minus kudzuvine root group, Sijunzitang group and Qiweibaizhusan group. The control group was treated with boiled water, the antibiotics group was treated with antibiotics mixture composed of gentamycin sulfate and cefradine, all other groups were treated with antibiotics mixture and Chinese medicines. After three days of treatment with Chinese medicine, the intestinal microbes and enzyme activities of intestinal contents were measured. The results showed that the color of mice feces turned from black to yellow, the diarrhea mice treated by the minus kudzuvine root group and Qiweibaizhusan group were cured. Compared to the antibiotics group, the amount of bacteria from the minus kudzuvine root group and Qiweibaizhusan group showed significant reduction $(\mathrm{P}<0.05)$. Compared to the control group, the amounts of Bifidobacterium spp. and Lactobacillus spp. from each treated group significantly increased $(\mathrm{P}<0.05)$.Compared to the control group the amounts of bacteria, Bifidobacterium spp. and Lactobacillus spp. from the antibiotics treated group, significantly reduced $(\mathrm{P}<0.05)$, but the amount of fungi was significantly increased $(\mathrm{P}<0.05)$.Compared to the antibiotics group, the amount of fungi from each Chinese medicine treated group significantly increased $(\mathrm{P}<0.05)$. Compared to the control group, intestinal enzyme activity from every treated group significantly reduced $(\mathrm{P}<0.05)$. Compared to the antibiotics treated model group, protease and amylase activities from each every Chinese medicine treated group were significantly higher $(\mathrm{P}<0.05)$. Xylanase activities of the minus agastache group and Qiweibaizhusan group were significantly lower than that of antibiotics treated group, the minus agastache group and Sijunzitang group $(\mathrm{P}<0.05)$. The ingredients of tonifying qi which exist mainly in Sijunzitang, Ginseng, Rhizoma Atractylodis and Poria cocos, are the key Chinese medicine for the regulation of intestinal physiological flora. Agastache and costustoot played important roles on anti-diarrhea by inhibiting the growth of bacteria and the xylanase activity, and kudzuvine root had the function on improving the amylase activity.
\end{abstract}

Keywords: Qiweibaizhusan, sijunzitang, intestinal microorganisms, enzyme activity

\section{Introduction}

Compound traditional Chinese medicine is one of the medication characteristics of traditional Chinese medicine, as well as its essence. Compatibility regularity of compound Chinese medicine is rich and colorful, containing mutual promotion, mutual enhancement, mutual inhibition and incompatibility between each Chinese herbal medicine [1-2]. According to the traditional Chinese medicine theory, every herbal medicine statuses in the prescription included Monarch, minister, assistant and guider, we can determine the main herb, active substance of Chinese herb compound further and confirm the scientific property of prescription compatibility by minus one herbal medicine of the prescription. Qiweibaizhusan is a millennium ancient prescription to treat pediatric diarrhea, and it has stringent design and accurate appropriate compatibility. Qiweibaizhusan was modified on the basis of Sijunzitang. Previous studies confirmed both Qiweibaizhusan and
Sijunzitang had very good efficacy on diarrhea caused by antibiotics [3]. The use of antibiotic is bound to affect the changes of intestinal flora [3-5], and the intestinal flora has a crucial effect on host's metabolic function and life activities [6-7]. The intestinal flora and enzyme devoted to dissolution and transformation of the Chinese herbal medicinal ingredients by hydrolysis and restoring reaction [8]. While the ingredients of Chinese herb medicine had an effect on intestinal flora and enzyme [9-11]. So, the change of intestinal microflora and enzyme activity can reflect the efficacy mechanisms of some medicine. This study was guided by basic theories of Chinese medicine, microbial culturing methods and enzymological methods combining with jianwei method were used to investigate the effects of Sijunzitang, jianwei Qiweibaizhusan and Qiweibaizhusan on microorganism and enzyme activity in intestine, which were devoted to support the science of compatibility of Chinese medicine prescription. 
Materials and methods

Experimental animals

70 Kunming mice (SPF grade) were provided by Shanghai Experimental Animal Center of Chinese Academy of Sciences. The weight of each mouse was about $20 \pm 2 \mathrm{~g}$. Mouse food was provided by Experimental Animal Center of Hunan University of Traditional Chinese Medicine. The mice were divided into 7 groups (10 mice per group): the control group, the antibiotics treated the model group, the minus agastache group, the minus costustoot group, minus kudzuvine root group, the Sijunzitang group and Qiweibaizhusan group.

\section{Drug treatment}

The gentamycin sulfate and cefradine were mixed with the concentration was $62.5 \mathrm{~g} \cdot \mathrm{L}^{-1}$. The control group's mice were treated with boiled water $(0.35 \mathrm{~mL} / \mathrm{mouse})$ by oral administration with gavage, and the rest of group's mice were treated with antibiotic mixture $(0.35 \mathrm{~mL} / \mathrm{mouse})$ by gavage [12], twice a day, for $5 \mathrm{~d}$.

Qiweibaizhusan was prepared according to the Chinese Pharmacopoeia, which was composed of ginseng of $6 \mathrm{~g}$, costustoot of $6 \mathrm{~g}$, poria cocos of $10 \mathrm{~g}$, roasted rhizoma atractylodis macrocephalae of $10 \mathrm{~g}$, pueraria of 10 $\mathrm{g}$, agastache of $10 \mathrm{~g}$ and liquarice of $3 \mathrm{~g}$. Each jianwei Qiweibaizhusan were prepared by minus a single Chinese herb that was based on the drug dose of Qiweibaizhusan. Sijunzitang was composed of ginseng $9 \mathrm{~g}$, poria cocos of 9 $\mathrm{g}$, rhizoma stractylodis macrocephalae of $9 \mathrm{~g}$ and liquarice of $6 \mathrm{~g}$. Each Chinese herb was provided and identified by the first hospital of Hunan University of TCM.

Each jianwei Qiweibaizhusan and Sijunzitang were made into water decoction of appropriate concentration stored at $4{ }^{\circ} \mathrm{C}$. The control group's mice were still treated with boiled water during the treatment, the other group's mice were treated with oral water decoction of Chinese medicine according to the clinical equivalent dosage of mice, the dosage for the minus agastache group's mice were treated with dose of $2.59 \mathrm{~g} \cdot \mathrm{kg}^{-1} \cdot \mathrm{d}^{-1}$, the minus costustoot group's mice were treated with dose of $2.83 \mathrm{~g} \cdot \mathrm{kg}^{-1} \cdot \mathrm{d}^{-1}$, the minus pueraria group's mice were treated with dose of $2.59 \mathrm{~g} \cdot \mathrm{kg}^{-1} \cdot \mathrm{d}^{-1}$, Qiweibaizhusan group's mice were treated with dose of $3.16 \mathrm{~g} \cdot \mathrm{kg}^{-1} \cdot \mathrm{d}^{-1}$ and Sijunzitang group's mice were treated with dose of $1.91 \mathrm{~g} \cdot \mathrm{kg}^{-1} \cdot \mathrm{d}^{-1}$ [12]. All the drugs were orally administered to the mice by a gavage twice a day, once the diarrhea of any group's mice were cured, the treatment of all groups would be stopped. In fact, the treatment with Chinese medicine last only three days.

\section{Medium}

Beef extract-peptone medium for bacteria, EMB medium for colibacillus, MRS medium for lactobacillus, BBL medium for bifidobacteria and martin Rose Bengal Medium for fungi were prepared according to previous description [13-15]. Clostridium difficile Moxalactam Norfloxacin (CDMN) agar medium was used for couting Clostridium difficile.

\section{Extraction of intestinal contents}

All the mice were sacrificed on the morning of the ninth day after treatment. Mouse intestinal (jejunum to the rectum) contents were collected in a steriled environment.

\section{Determination of microorganisms of intestinal contents}

A certain amount of intestinal contents were weighed in a steriled environment and transferred into conical flask equipped with glass beads and steriled water. In order to release microorganisms from intestinal contents into steriled water completely, the conical flasks were put on an oscillators for $30 \mathrm{~min}$ with $120 \mathrm{rpm}$ shaking. The number of microorganisms of intestinal contents was determined with the method of plate culturing counting. Total numbers of bacteria and colibacillus were counted after being cultured for 24 hours at $37^{\circ} \mathrm{C}$. Total numbers of 1actic acid bacteria, bifidobacteria and fungi were determined after being cultured for 48 hours at $37^{\circ} \mathrm{C}$. The numbers of Clostridium difficile were determined after being cultured for 72 hours at $37^{\circ} \mathrm{C}$ under $80 \%$ nitrogen, $10 \%$ carbon dioxide and $10 \%$ hydrogen enviroment.

\section{Analyze enzyme activities of intestinal contents}

To dissolve enzyme from intestinal contents completely, the contents were diluted with steriled water and heated preservation for $30 \mathrm{~min}$ water bath $\left(40^{\circ} \mathrm{C}\right)$. The enzyme crude extracts were centrifuged for $10 \mathrm{~min}$ at $2000 \mathrm{rpm}$ and the supernatants were collected for enzyme activity analysis. The activities of amylase, xylase and cellulase activity were determined by DNS colorimeter as previous described [16]. Cellulase activity was defined as an unit of the cellulase activity by generating $1 \mathrm{mg}$ reducing sugar of $1 \mathrm{~g}$ contents at $46^{\circ} \mathrm{C}$ for $30 \mathrm{~min}$. Amylase activity was defined as an unit of the amylase activity by generating $1 \mathrm{mg}$ reducing sugar of $1 \mathrm{~g}$ contents at $37^{\circ} \mathrm{c}$ for $60 \mathrm{~min}$. Xylase activity was defined as an unit of the xylase activity by generating $1 \mathrm{mg}$ reducing sugar of $1 \mathrm{~g}$ contents at $46^{\circ} \mathrm{C}$ for $60 \mathrm{~min}$. Protease activity was determined by Folinphend method [17]. Protease activity was defined as an unit of protease activity by generating $1 \mathrm{~g}$ amino acid of 1 g contents at $37^{\circ} \mathrm{C}$ for $40 \mathrm{~min}$.

\section{Statistical analysis}

Measurement data of every group were represented with mean-standard deviation ( $\mathrm{x} \pm \mathrm{s}$ ) and analyzed using DPS v7.05 statistical software.

\section{Results}

The apparent characteristics of mices were observed The time for initiating diarrhea in mice required 5 days of antibiotic treatment, and the Chinese medicine treatment started in the sixth day. Once any group of mice with 
Cai et al. Journal of Pharmaceutical Technology \& Drug Research 2013, http://www.hoajonline.com/journals/pdf/2050-120X-2-6.pdf

Table 1. Effect of jianwei Qiweibaizhusan on treatment of dysbacteriosis in mice.

\begin{tabular}{lcc}
\hline & $\begin{array}{l}\text { The dilution of } \\
\text { feces after molding }\end{array}$ & $\begin{array}{l}\text { The dilution of } \\
\text { feces after treatment }\end{array}$ \\
\hline control group & ++ & ++ \\
model group & --- & -- \\
minus agastache group & --- & - \\
minus costustoot group & --- & - \\
minus kudzuvine root group & --- & + \\
Sijunzitang group & --- & - \\
Qiweibaizhusan group & --- & + \\
\hline
\end{tabular}

Note: + constipation; - wet feces.

Table 2. Effect of jianwei Qiweibaizhusan on specific intestinal microbes in mice.

\begin{tabular}{lllll}
\hline & $\begin{array}{l}\text { colibacillus } \\
\left(\mathbf{1 0} \mathbf{C F U}^{6} \mathbf{g}^{-1}\right)\end{array}$ & $\begin{array}{c}\text { lactobacillus } \\
\left(\mathbf{1 0} \mathbf{C}^{8} \mathrm{CF} \cdot \mathbf{g}^{-1}\right)\end{array}$ & $\begin{array}{l}\text { bifidobacteria } \\
\left(\mathbf{1 0}^{7} \mathrm{CFU} \cdot \mathbf{g}^{-1}\right)\end{array}$ & $\begin{array}{l}\text { C. difficile } \\
\left(\mathbf{1 0} \mathbf{C F U}^{5} \mathbf{g}^{-1}\right)\end{array}$ \\
\hline $\begin{array}{l}\text { control group } \\
\text { model group }\end{array}$ & $5.89 \pm 0.80$ & $4.71 \pm 0.76$ & $6.79 \pm 0.43$ & $2.85 \pm 0.32$ \\
$\begin{array}{l}\text { minus agastache } \\
\text { group }\end{array}$ & $5.72 \pm 0.32$ & $3.11 \pm 0.21^{\mathrm{A}}$ & $4.74 \pm 0.21^{\mathrm{A}}$ & $8.63 \pm 0.25^{\mathrm{a}}$ \\
$\begin{array}{l}\text { minus costustoot } \\
\text { group }\end{array}$ & $5.44 \pm 0.26$ & $6.77 \pm 0.23^{\mathrm{Ab}}$ & $8.94 \pm 0.82^{\mathrm{Ab}}$ & $3.61 \pm 0.75^{\mathrm{b}}$ \\
$\begin{array}{l}\text { minus kudzuvine } \\
\text { root group }\end{array}$ & $5.21 \pm 0.56$ & $6.27 \pm 0.34^{\mathrm{Ab}}$ & $8.41 \pm 0.57^{\mathrm{Ab}}$ & $3.65 \pm 0.56^{\mathrm{b}}$ \\
$\begin{array}{l}\text { Sijunzitang group } \\
\text { Qiweibaizhusan }\end{array}$ & $4.98 \pm 0.28$ & $8.89 \pm 1.01^{\mathrm{abCDE}}$ & $11.84 \pm 2.46^{\mathrm{abCDE}}$ & $3.50 \pm 0.38^{\mathrm{b}}$ \\
group & $5.04 \pm 0.37$ & $7.07 \pm 1.21^{\mathrm{ab}}$ & $9.35 \pm 1.80^{\mathrm{AbF}}$ & $3.02 \pm 0.49^{\mathrm{b}}$ \\
\hline
\end{tabular}

CFU: Colony forming units.

Compared to control group: $\mathrm{A}: \mathrm{P}<0.05, \mathrm{a}: \mathrm{P}<0.01$; Compared to antibiotics treated group: $\mathrm{B}: \mathrm{P}<0.05, \mathrm{~b}: \mathrm{P}<0.01$; Compared to minus agastache group: $\mathrm{C}: \mathrm{P}<0.05, \mathrm{c}: \mathrm{P}<0.01$;Compared to minus costustoot group: $\mathrm{D}: \mathrm{P}<0.05, \mathrm{~d}: \mathrm{P}<0.01$; Compared to minus kudzuvine root group: $\mathrm{E}: \mathrm{P}<0.05 ; \mathrm{e}: \mathrm{P}<0.01$;Compared to Sijunzitang group: $\mathrm{F}: \mathrm{P}<0.05, \mathrm{f}: \mathrm{P}<0.01$.

diarrhea recovered, the Chinese medicine treatment would be ended and it lasted 3 days. Then the intestinal contents of mice were sampled and analyzed. Through the observation of inherent moisture and color of fresh feces from mice in pretherapy and post-treatment, the feces of control group's mice was more desiccation than the other group's mice and its color was yellow. On the 3rd day the antibiotics treatment group's mice did not appeared diarrhea but their feces' color turned from yellow to black. On the 5th day the color of feces remained black and most of the antibiotic treatment mice appeared to moderate diarrhea (Table 1). The external features displayed that the mice diarrhea model were successful established. After dissection of the diarrhea mice, we found the cecum was obvious swelling and engorged, the bowel wall turned to thinner and covered with red small blood spot, those may be the reason that the fresh feces of diarrhea mice turned to black. antibiotics could damage the bowel wall and led to hemorrhaged. Histology detection of intestinal mucosa need to futher confirmation. During the period of Chinese medicine treatment, the fresh feces was black and moist in mice of all groups except for the control group in the 1st day, and it was still moist in the 2nd day, the fresh feces was black in mice of antibiotics treatment group, but yellow in mice of all Chinese medicine treatment groups. In the 3th day during the period of Chinese medicine treatment, the color of all mice' fresh feces went to normal color, and the fresh feces were wet in mice of the minus agastache group, minus costustoot group and Sijunzitang group. The diarrhea was disappeared in mice of the minus kudzuvine root group and Qiweibaizhusan group (Table 1). The results may be due to anti-diarrhea effects of both costustoot and agastache. After Chinese medicine treatment, the mice were dissected, and it showed the cecums were swelling and engorged in mice of the antibiotic trearment group except for the contral group. There were still some red small blot spot in mice of antibiotics treated model group, and less red small blot spot or none in mice of the Chinese medicine treated groups. These intestinal external characteristic displayed intestinal wall of Chinese medicine treatment group's mice recovered well, histology detection of intestinal mucosa need to futher confirmation. Some antibiotic treatment mice showed depressed, drowsiness, and chilly during the antibiotics treatment times, and these symptoms tended to disappear during the Chinese medicine treatment times. The weight growth of antibiotic treatment mice was smaller than that of the control group mice during the antibiotics treatment times, it was then steady in all mice during Chinese medicine treatment time.

\section{Effects of jianwei Qiweibaizhusan on the intestinal microorganisms}

Mice intestinal contents were collected in a steriled environment, and the microorganisms in the intestinal contents were detected by plate counting method. The amount of E.coli restored to normal level $(P>0.05)$ rapidly after antibiotic treatment (Table 2), but the amount of Lactobacillus spp. and Bifidobacterium spp. which were probiotics in the intestine were significantly declined $(P<0.05)$ and restored slowly in antibiotics treated mice, and increased significantly and beyond the normal level $(P<0.05)$ after being treated by Chinese medicine. Especially the amount of Bifidobacterium spp. of Sijunzitang group had increased significantly compared with the other Chinese medicine treatment groups $(P<0.05)$, suggesting that Chinese medicine had enhancing effect on intestinal probiotics. At the same time, the amount of $C$. difficile significantly increased in antibiotics treated mice $(P<0.01)$ and restored to normal level $(P>0.05)$ after being treated by Chinese medicine. It suggested that Chinese medicine can inhibit C. difficile and Qiweibaizhusan is better than Sijunzitang.

\section{Effects of jianwei Qiweibaizhusan on intestinal fungi} and bacterial in mice

In the strict sense, aerobic bacteria in intestinal contents, which grew in beef extract-peptone medium, were opportunistic pathogens and pathogenic bacteria. The 


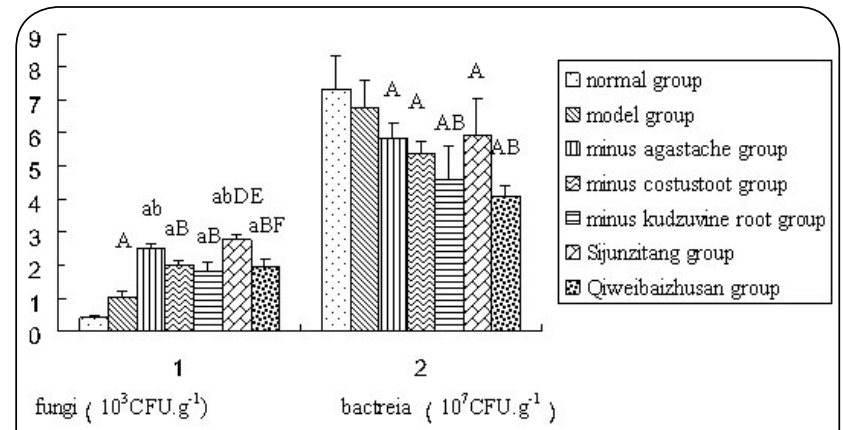

Figure 1. Effect of jianwei Qiweibaizhusan on intestinal fungi and bacterial in mice.

Compared to control group: $\mathrm{A}: \mathrm{P}<0.05, \mathrm{a}: \mathrm{P}<0.01$; Compared to the antibiotics treated group: $\mathrm{B}: \mathrm{P}<0.05, \mathrm{~b}: \mathrm{P}<0.01$; Compared to the minus agastache group: $\mathrm{C}: \mathrm{P}<0.05, \mathrm{c}: \mathrm{P}<0.01$; Compared to the minus costustoot group: $\mathrm{D}: \mathrm{P}<0.05, \mathrm{~d}: \mathrm{P}<0.01$; Compared to the minus kudzuvine root group: $\mathrm{E}: \mathrm{P}<0.05 ; \mathrm{e}: \mathrm{P}<0.01$; Compared to the Sijunzitang group: $\mathrm{F}: \mathrm{P}<0.05, \mathrm{f}: \mathrm{P}<0.01$.

Table 3. Effects of jianwei Qiweibaizhusan on intestinal enzyme activity in mice.

\begin{tabular}{lllll}
\hline & xylase $(U)$ & amylase $(U)$ & cellulase $(U)$ & protease $(U)$ \\
\hline $\begin{array}{l}\text { control group } \\
\text { model group }\end{array}$ & $8.15 \pm 0.46$ & $44.21 \pm 2.75$ & $2.31 \pm 0.51$ & $7.54 \pm 0.43$ \\
$\begin{array}{l}\text { minus agastache } \\
\text { group }\end{array}$ & $4.81 \pm 0.03^{\mathrm{a}}$ & $28.03 \pm 2.60^{\mathrm{AB}}$ & $1.83 \pm 0.23^{\mathrm{A}}$ & $5.39 \pm 0.15^{\mathrm{AB}}$ \\
$\begin{array}{l}\text { minus costustoot } \\
\text { group }\end{array}$ & $22.32 \pm 1.61^{\mathrm{a}}$ & $1.47 \pm 0.28^{\mathrm{A}}$ & $4.07 \pm 0.59^{\mathrm{A}}$ \\
$\begin{array}{l}\text { minus kudzuvine } \\
\text { root group }\end{array}$ & $3.84 \pm 0.34^{\mathrm{a}}$ & $29.82 \pm 2.64^{\mathrm{AB}}$ & $1.67 \pm 0.09^{\mathrm{A}}$ & $5.41 \pm 0.23^{\mathrm{AB}}$ \\
$\begin{array}{l}\text { Sijunzitang group } \\
\text { Qiweibaizhusan }\end{array}$ & $4.71 \pm 0.17^{\mathrm{aE}}$ & $31.04 \pm 1.21^{\mathrm{ABE}}$ & $1.72 \pm 0.17^{\mathrm{A}}$ & $6.16 \pm 0.94^{\mathrm{AB}}$ \\
group & $3.06 \pm 0.39^{\mathrm{aBCF}}$ & $29.29 \pm 1.97^{\mathrm{AB}}$ & $1.69 \pm 0.08^{\mathrm{A}}$ & $6.02 \pm 0.61^{\mathrm{AB}}$ \\
\hline
\end{tabular}

Compared to control group: $\mathrm{A}: \mathrm{P}<0.05, \mathrm{a}: \mathrm{P}<0.01$; Compared to the antibiotics treated group: $\mathrm{B}: \mathrm{P}<0.05, \mathrm{~b}: \mathrm{P}<0.01$; Compared to the minus agastache group: $\mathrm{C}: \mathrm{P}<0.05, \mathrm{c}: \mathrm{P}<0.01$; Compared to the minus costustoot group: $\mathrm{D}: \mathrm{P}<0.05, \mathrm{~d}: \mathrm{P}<0.01$; Compared to the minus kudzuvine root group: $\mathrm{E}: \mathrm{P}<0.05 ; \mathrm{e}: \mathrm{P}<0.01$; Compared to the Sijunzitang group: F:P $<0.05, \mathrm{f}: \mathrm{P}<0.01$.

bacteria in model group recovered faster than the other Chinese medicine groups $(P>0.05)$, bacteria amount of Chinese medicine treatment groups recovered more slower than the control group $(P<0.05)$, especially it reduced significantly in the minus kudzuvine root group and Qiweibaizhusan group compared to the control group $(P<0.05)$ (Figure 1$)$. It may be due to agastache's and costustoot's inhibitory effect on intestinal bacteria. Compared to the control group the amount of bacteria, Bifidobacterium spp. and Lactobacillus spp. of antibiotic treatment group significantly reduced, but fungi significantly increased $(P<0.05)$ (Table 2 and Figure 1). It may be due to the use of antibiotics which had only inhibitory effect on intestinal bacteria, thus led to fungal growth competitively. While the amount of bacteria, Bifidobacterium spp. and Lactobacillus spp. was significantly increased in all Chinese medicine treatment group compared to the control group and the model group $(P<0.05)$, and the amount of fungi significantly increased in Sijunzitang group compared with the minus costustoot group, minus kudzuvine root group, or Qiweibaizhusan group $(P<0.05)$, suggesting that the promoting ingredients of fungi growth mainly exited in sijunzitang treated group. It had reported that agastache could inhibit the growth of fungi in vitro experiments of antibacterial [18], which was confirmed in vivo in our study. The intestinal fungi included beneficial yeast (Saccharomyces cerevisiae) and opportunistic pathogens (Candida albicans, Molds), It depends on the further study whether Qiweibaizhusan only has promoting effect on the growth of intestinal beneficial fungi.

\section{Effects of jianwei Qiweibaizhusan on mice intestinal enzyme activities}

The amylase and protease are pivotal digestive enzymes in intestine which are mainly secreted by the body itself. If the activity of amylase and protease decline, body's digestion and absorption function will certainly be affected. The mouse intestinal mucosa was damaged by flowing the antibiotic intervention which must be influence the activity of digestive enzymes. Table 3 showed that the activities of amylase and protease of the treatment groups were lower than that of control group $(P<0.05)$, which explained the damage of intestinal mucosa affected the activity of intestinal enzyme (Table 3). Qiweibaizhusan and Sijunzitang had enhanced function on the repair of intestinal mucosa combining with apparent characteristics of mice, but the intestinal wall did not repair completely after only three days' treatment which depended on the unrecovered enzyme activities of amylase and protease. The protease activities of each jianwei Qiweibaizhusan and Sijunzitang group were higher than that of the antibiotics treated group $(P<0.05)$, probably due to its enhancing promoting function of the intestinal wall's repairmen, and also there may be some ingredients of Qiweibaizhusan and Sijunzitang that could improve protease activity, which needed further study. The amylase activity of each Chinese medicine treated group was higher than that of the antibiotics treated group $(P<0.05)$, and amylase activity of the minus kudzuvine root group was lower than that of the Sijunzitang group $(P<0.05)$, suggesting amylase activity could be improved by adding of the kudzuvine root.

The enzyme activities of cellulase and xylanase which are secreted only by intestinal microbial were very low in intestine, and the diversification of them reflected the changes of microbial species which could secrete these kinds of enzymes. Compared to the control group, cellulase and xylanase activities were significantly decreased in each treatment group $(P<0.05)$, and it illustrated that antibiotics inhibited the growth of microbes which can secrete xylanase and cellulase (Table 3). Combining with Table 1, the microbes 
of each treatment group had been restored to normal levels, even the amount of probiotics was larger than that of the control group for three days treatment. But the function of intestine microbes could not restore completely in a short treatment time. The xylanase activities of the minus kudzuvine root group and the Qiweibaizhusan group were lower than that of the antibiotics treated group, minus agastache group, and the Sijunzitang group $(P<0.05)$, which may illustrated that agastache and costustoot could synergistically inhibit microorganisms which secreted xylanase, and the inhibiting ability of agastache was stronger than that of costustoot. The cellulase activity in the intestine was extremely low, which was no significant change through pairwise comparisons $(P>0.05)$ after the treatment.

\section{Discussion}

Spleen governed movement and transformation, and spleen deficiency led to dysfunction of digesting food and water, and lesions appeared such as diarrhea, asthenia of qi and blood, weight loss and so on [19]. According to the literature we have consulted, most of the modern research of the TCM on spleen function are focused on the symptoms of spleen deficiency. Using the binding methods of feeding colchicines, diarrhea of bitter-cold, abnormal of starvation and full and excessive labor to create the rat model of spleen deficiency [20], but such methods to explain its function were limited by lack of diversity. The research of spleen deficiency should primarily focus on the function of moving and transforming food essence. In this study, we adopted the method of antibiotics combination to make animal diarrhea model, we could see from the apparent characteristics that the mice presented appeared the similar symptoms of spleen deficiency, as well as diarrhea, listlessness and slowed weight growth, and we could see from the effect of Qiweibaizhusan on gut microbes and enzyme activities showed that the microecological balance was disrupted and the intestinal enzyme activities were declined.

Qiweibaizhusan derived from Sijunzitang which was the basic prescription of treating spleen and stomach qi deficiency. Qiweibaizhusan was indicated in spleen and stomach deficiency, Vomiting diarrhea, loss of apepetite thin and weak, spleen and stomach deficiency were the essence of disease, weak and diarrhea were the appearance of disease, Agastache, costustoot and kudzuvine root could cure the appearance of disease. Our experimental results suggested that Sijunzitang's promoting function of the growth of beneficial bacteria was stronger than that of all kinds of jianwei Qiweibanzhusan, and whole Qiweibaizhusan. Sijunzitang's promoting effect of amylase activity were stronger than that of the minus kudzuvine root. So its tonifying qi function were superior to Qiweibaizhusan. For the appearance of desease, the diarrhea condition of Sijunzitang group's mice were not restored after 3 days of treatment, but Qiweibanzhusan group's mice were restored well, which suggested agastache, costustoot and kudzuvine root could cure the appearance of disease, and the experiment results also confirmed the Chinese medicine theory.

Through the impact, constraint and interact each other mutually, intestinal flora form a physiological combination according to a certain proportion. The combination had a certain volatility. Once the combination beyond wave range to produce a pathology, it will cause the diarrhea due to intestinal flora imbalance. According to this study, the physiological combination of Sijunzitang was the superior, so the prebiotics composition of Qiweibaizhusan mainly existed in Sijunzitang. Many researchers reported that there were probiotics composition in Sijunzutang [21-22], the prebiotic products developed were oligosaccharide and polysaccharide,atractlodes macrocephalaon polysaccharide(the main ingredient were mannan and fructan), ginseng polysaccharides and pachyman may be the key pharmacological composition in Sijunzitang to regulate flora.

Monarch, minister, assistant and guide are the composition prescription of traditional Chinese medicine. Ginseng, rhizoma Atractylodis Macrocephalae and poria cocos were monarch drug which could tonifying qi and spleen. Agastache rugosus and elecampane eliminated dampness with aromatics. Combination with the results Agastache rugosus and elecampane had the function on collaborative anti-diarrhea by inhibiting the growth of aerobic bacteria and decreasing the activity of xylanase, but the function on antifungal and inhibiting xylanase activity of agastanche rugosus was superior to elecampane, so agastanche rugosus was minister drug and elecampane was assistant drug. Pueraria could relieved superficial and dirrahea. Combination with our results we could see that the function on anti-dirrahea of pueraria were less than that of agastache rugosus and elecampane, but pueraria could increase amylase activities by collaborating with monarch drugs, so both pueraria and elecampane were assistant drugs. Liquorice was a guide drug which benefited qi for regulating stomach and harmonizing all herb medicines. On the basis of the analyses above, we may draw a conclusion that Qiweibaizhusan could cure diarrhea caused by antibiotic very well and the compatibility of Qiweibaizhusan was highly scientific.

\section{Competing interests}

The authors declare that they have no competing interests.

\section{Authors' contributions}

GuangXian Cai and Ao Zeng were the first co-authors. GuangXian Cai made substantial contributions to conception and design and coordination. Ao Zeng participated in its design and acquisition of data and helped to draft and revise the manuscript. NenQun Xiao made substantial contributions to analysis and interpretation of data. SaiNan Zhou made substantial contributions to analysis of data. KangXiao Guo made substantial contributions to interpretation of data. 
ZhouJin Tan conceived of the study, and participated in its design and coordination and helped to draft and revise the manuscript. All authors read and approved the final manuscript. There won't be any further changes in the authorship which includes either addition or removal of author's details and ZhouJin Tan will be sole responsible person for all the communications and proceedings that are needed to be done with the publisher (According to the necessity of the publisher) on behalf of all the authors.

Acknowledgement and funding

We are grateful to the financial support of the National

Natural Science Foundation of China (81173214). We also acknowledged Dr XinHua Shu who provided writing assistance. Dr XinHua Shu is working in Department of Life Sciences, Glasgow Caledonian University, Glasgow G4 OBA, United Kingdom.

\section{Publication history}

Received: 29-Dec-2012 Revised: 19-Jan-2013

Re-Revised: 24-Jan-2013 Accepted: 29-Jan-2013

Published: 02-Feb-2013

\section{References}

1. Li S, Zhang B, Jiang D, Wei Y, Zhang N: Herb network construction and co-module analysis for uncovering the combination rule of traditional Chinese herbal formulae. BMC Bioinformatics 2010, 11 Suppl 11:S6. | Article | PubMed Abstract | PubMed Full Text

2. Shang $\mathrm{HC}$,Zhang $B L, G a o X M$ : Investigating the compatibility of chinese medicine prescription. Chines journal of information on TCM 2002, 9:6-8.(in chinese).

3. Zhao AG, Zhao HL, Jin XJ, Yang JK, Tang LD: Effects of Chinese Jianpi herbs on cell apoptosis and related gene expression in human gastric cancer grafted onto nude mice. World J Gastroenterol 2002, 8:792-796. | Article | PubMed

4. Dethlefsen L, Relman DA: Incomplete recovery and individualized responses of the human distal gut microbiota to repeated antibiotic perturbation. Proc Natl Acad Sci USA 2011, 108 Suppl 1:4554-4561. I Article | PubMed Abstract | PubMed Full Text

5. John G, Bartlett MD: Antibiotic-Asoociated diarrhea. BMJ 2002, 324:1345-1346. | Article

6. Backhed F: Addressing the gut microbiome and implications for obesity. International Dairy Journal 2010, 20:259-261. I Article

7. Cho I, Yamanishi S, Cox L, Methe BA, Zavadil J, Li K, Gao Z, Mahana D, Raju K, Teitler I, Li H, Alekseyenko AV, Blaser MJ: Antibiotics in early life alter the murine colonic microbiome and adiposity. Nature 2012, 488:621-626. | Article | PubMed

8. Vitali B, Ndagijimana M, Cruciani F, Carnevali P, Candela M, Guerzoni $\mathrm{ME}$, Brigidi $\mathrm{P}$ : Impact of a synbiotic food on the gut microbial ecology and metabolic profiles. BMC Microbiol 2010, 10:4. | Article | PubMed Abstract | PubMed Full Text

9. Deng ZY, Zhang JW, Li J, Fan YW, Cao SW, Huang RL, Yin YL, Zhong HY, Li TJ: Effect of polysaccharides of cassiae seeds on the intestinal microflora of piglets. Asia Pac J Clin Nutr 2007, 16 Suppl 1:143-147. | $\underline{\text { Pdf I PubMed }}$

10. Fugh-Berman A: Herb-drug interaction. Lancet 2000, 355:134-38. | $\underline{\mathrm{Pdf}}$

11. Elgayyar M, Draughon FA, Golden DA, Mount JR: Antimicrobial activity of essential oils from plants against selected pathogenic and saprophytic microorganisms. J Food Prot 2001, 64:1019-1024. | Article I PubMed

12. He SL,Wang J.Wang JJ: Traditional Chinese medicine scientific research design and statistics, Changsha. Hunan Science and Technology Press 2006, p.48-59.(in chinese).

13. Shen P,Chen XD: Microbiology experiment. Peking:Higher education press 2008, p.251-253.(in chinese).
14. Ling DW: Actic acid bacteria classification and identification and experimental method. Peking: China Light Industry Press 1999, p.8586. (in chinese).

15. Zhang CW: Sanitary microbiology. Peking:People's Medical Publishing House, peking 2007, (in chinese).

16. Gusakov AV, Kondratyeva EG, Sinitsyn AP: Comparison of two methods for assaying reducing sugars in the determination of carbohydrase activities. Int J Anal Chem 2011, 2011:283658. I Article | PubMed Abstract | PubMed Full Text

17. Ledoux M, Lamy F: Determination of proteins and sulfobetaine with the Folin-phenol reagent. Anal Biochem 1986, 157:28-31. | Article | PubMed

18. Shin S, Pyun MS: Anti-Candida effects of estragole in combination with ketoconazole or amphotericin B. Phytother Res 2004, 18:827830. | Article | PubMed

19. Xue XL, Wu XY, Xing JM, Li L, Zhao Y, Wang JJ, Zhang YJ, Wang QB, Tang Y, Li GR, Han P, Li Z, Wang WP, Wang TF: Xiaopiyishen Herbal Extract Granule Improves the Quality of Life among People with FatiguePredominant Subhealth and Liver-Qi Stagnation and Spleen-Qi Deficiency Syndrome. Evid Based Complement Alternat Med 2012, 2012:509705. | Article | PubMed Abstract | PubMed Full Text

20. Shen LB,Qian HN: Progress on research methods of establishing spleen deficiency model. Chinese journal of information on traditional chinese medicine 2005, 12:93-95.(In chinese).

21. Jiang LZ,Zhao CQ: Chinese medicine and microecolog. Peking:Chemical industry press 2008, (in Chinese).

22. Li H, Zhou M, Zhao A, Jia W: Traditional Chinese medicine: balancing the gut ecosystem. Phytother Res 2009, 23:1332-1335. | Article | $\underline{\text { PubMed }}$

\section{Citation:}

Cai G, Zeng A, Xiao N, Zhou S, Guo K and Tan Z:

Effects of jianwei qiweibaizhusan on the intestinal microorganisms and enzyme activities. journal of Pharmaceutical Technology and Drug Research 2013, 2:6. http://dx.doi.org/10.7243/2050-120X-2-6 